\title{
Modelagem matemática nos anos iniciais do Ensino Fundamental: uma proposta para $05^{\circ}$ ano
}

Mathematical modeling in the initial years of Elementary School

Ieda Maria Giongo ${ }^{1}$

Magáli Schuster Kuhn²

\section{Resumo}

Este artigo relata algumas ações de uma pesquisa intervenção que teve como foco a Modelagem Matemática nos Anos Iniciais do Ensino Fundamental. A questão de pesquisa Quais as possibilidades e limitações de uma prática pedagógica investigativa efetivada em uma turma de $5^{\circ}$ ano do Ensino Fundamental tendo como aportes teóricos estudos do campo da Modelagem Matemática? - delineou os objetivos que se constituem em avaliar as contribuições da prática pedagógica na reflexão crítica do aluno frente a questões sociais; promover nos discentes a capacidade de fazer uso de conhecimentos vinculados à disciplina de Matemática em outras áreas do conhecimento e em situações cotidianas, bem como contribuir para a disseminação de conhecimentos relativos à Modelagem Matemática nos Anos Iniciais do Ensino Fundamental. O referencial teórico está alicerçado em conceitos e contribuições de Biembengut e Hein (2005), Burak e Aragão (2012), Barbosa (2001, 2004), Silva e Barbosa (2011) e Silva, Barbosa e Oliveira (2013). Os conteúdos matemáticos abordados emergiram de temas de interesse dos estudantes, evidenciados por meio de diálogos efetivados no início da referida prática, que ocorreu nos meses de março, abril e maio de 2015, em uma escola pública da Região do Vale do Taquari, RS. Os resultados provenientes da pesquisa apontam olhares para a escrita dos alunos; uso de diferentes formas de pensar matematicamente e crescimento da turma frente às questões sociais discutidas ao longo dos encontros.

Palavras chave: Matemática; Modelagem Matemática; Prática Pedagógica Investigativa; Anos Iniciais.

\section{Abstract}

This article reports some procedures of an intervention research which focused on Mathematical Modeling in the Early Years of Elementary School. The research question Which are the possibilities and limitations of an exploratory pedagogical practice carried out in a 5th year of Elementary School supported on Mathematical Modeling theoretical studies? - outlined the goals which were to assess contributions of educational practice in the critical reflection of students towards social issues; to promote the students' ability to use Mathematics knowledge in other areas of knowledge and in everyday situations as well as to

\footnotetext{
${ }^{1}$ igiongo@univates.br

2 magalischusterkuhn@gmail.com
} 
contribute for the dissemination of knowledge concerning Mathematical Modeling in the Early Years of Elementary School. Theoretical support is based on concepts and contributions of Biembengut and Hein (2005); Burak and Aragon (2012); Barbosa (2001, 2004); Silva and Barbosa (2011); and Silva, Barbosa and Oliveira (2013). Mathematical contents emerged from students' interest, confirmed through dialogs at the beginning of practice which occurred in March, April and May 2015 in a public school in the Taquari Valley Region - RS. The survey results focus on attention to students' writing; use of different ways of thinking mathematically; and class improvement facing social issues discussed along the meetings.

Keywords: Mathematics; Mathematical Modeling; Exploratory Pedagogical Practice; Early Years.

\section{Da temática de investigação e do referencial teórico}

Este artigo expressa os resultados de uma investigação desenvolvida ao longo do Trabalho de Conclusão do Curso de Pedagogia do Centro Universitário UNIVATES, apresentado em formato de monografia, realizado durante o segundo semestre de 2014 e o primeiro de 2015.

A investigação teve como problemática a elaboração uma prática pedagógica centrada nas teorizações do campo da Modelagem Matemática em uma turma de $5^{\circ}$ ano do Ensino Fundamental. Visto o problema de pesquisa, os objetivos que nortearam a investigação pautaram-se nos seguintes aspectos: avaliar as contribuições da prática pedagógica na reflexão crítica do aluno frente às questões sociais; promover, nos discentes, a capacidade de fazer uso de conhecimentos vinculados à disciplina de Matemática em outras áreas do conhecimento e em situações cotidianas; contribuir para a disseminação de conhecimentos relativos à Modelagem Matemática nos Anos Iniciais do Ensino Fundamental.

A temática de pesquisa emergiu do interesse das autoras, visto que, a Modelagem Matemática tem se caracterizado como um campo pouco explorado nos Anos Iniciais do Ensino Fundamental, fato constatado nas buscas desenvolvidas no Portal da Capes e Biblioteca Digital da UNIVATES. Por meio dessas buscas, observou-se que a tendência da Educação Matemática denominada Modelagem Matemática, mesmo sendo alvo de inúmeras pesquisas no âmbito dos Ensinos Fundamental e Médio, apresenta poucas produções no que se refere aos Anos Iniciais do Ensino Fundamental. Embora seja considerada uma proposta recente nesse nível de ensino, tendo por referência os poucos estudos desenvolvidos, a

[...] arte de expressar por intermédio da linguagem matemática situaçõesproblema de nosso meio, tem estado presente desde os tempos mais primitivos. Isto é, a modelagem é tão antiga quanto a própria Matemática, surgindo de aplicações na rotina diária dos povos antigos (BIEMBENGUT E HEIN, 2005, p.7).

Apesar de estar presente na história da humanidade desde os tempos mais antigos, a Modelagem Matemática nem sempre foi denominada da forma como hoje a conhecemos. De acordo com estudos de Biembengut e Hein (2005), a expressão "Modelagem" surgiu no período do Renascimento, acompanhada pelo surgimento das primeiras ideias da Física. Sobretudo, Blum \& Niss (1991) e Fiorentini (1996), citados por Barbosa (2001, p.1), 
apontam que "o movimento de Modelagem Matemática internacional e nacional tomou contorno nos últimos trinta anos, contando com a contribuição decisiva de matemáticos aplicados que migraram para a área da Educação Matemática." Contribuindo com essa temática, Biembengut e Hein (2005) também defendem a visão de que a Modelagem Matemática na educação é mais recente, levando em consideração que,

Nas últimas três décadas, a modelagem vem ganhando seu "espaço" em diversos países, nas discussões sobre o ensino e aprendizagem, com posicionamentos a favor e contra sua utilização como estratégia de ensino de Matemática. No Brasil, um dos primeiros trabalhos de modelagem no ensino foi do professor Aristides Camargos Barreto, da PUC do Rio de Janeiro, na década de 1970. A consolidação e difusão se efetuaram por vários professores, em particular, pelo professor Rodney Bassanezi, da Unicamp de Campinas-SP e seus orientandos [...] (BIEMBENGUT e HEIN, 2005, p. 7).

Barbosa (2001, p.1) aponta, a partir das contribuições de Fiorentini (1996), que "as experiências no Brasil possuem um forte viés antropológico, político e sociocultural, já que têm procurado partir do contexto sociocultural dos alunos e de seus interesses". Sobre isso, Barbosa (2001, p.1-2) acrescenta que, através dos subsídios de Kaiser-Messmer (1991), "...] esta pode ser considerada uma marca dos trabalhos brasileiros de Modelagem, ao contrário do movimento internacional que não apresenta esta preocupação de forma muito aparente".

Outra questão importante é o fato de, muitas vezes, não ter sido criado um modelo específico, ou nenhum, para o desenvolvimento de uma proposta de Modelagem Matemática. Isso vem ao encontro do que Barbosa (2001) apresenta de modo significativo em relação à corrente sociocrítica, que está engajada com o social e o contexto do aluno a fim de resolver situações-problema do dia a ia.

Referente à concepção de Modelagem Matemática defendida por Biembengut e Hein, os autores atestam que "A modelação matemática norteia-se por desenvolver o conteúdo programático a partir de um tema ou modelo matemático e orientar o aluno na realização de seu próprio modelo-modelagem" Biembengut e Hein (2005, p. 18). Dessa forma, temos a perspectiva de que a Modelagem Matemática é vista como uma ferramenta, uma abordagem pela qual se introduz conhecimentos matemáticos por meio de diferentes áreas do conhecimento. Esse conceito, defendido por Biembengut e Hein (2005), também sugere a obtenção e construção de modelos matemáticos que, seguidos de uma série de procedimentos (interação - matematização - modelo matemático), culminam em um modelo matemático.

Dionísio Burak, por sua vez, parte de uma perspectiva cognitivista, centrada na visão construtivista de aprendizagem, no sociointeracionismo e na aprendizagem significativa. $\bigcirc$ autor define Modelagem Matemática como "um conjunto de procedimentos cujo objetivo é construir um paralelo para tentar explicar, matematicamente, os fenômenos presentes no cotidiano do ser humano, ajudando-o a fazer predições e tomar decisões" Burak e Aragão (2012, p.88). Sua concepção de Modelagem Matemática parte de duas premissas: "1) o interesse do grupo de pessoas envolvidas; 2) os dados são coletados onde se dá o interesse do grupo de pessoas envolvidas" (Ibidem, p.88). Assim, nota-se que as atividades partem do grupo de indivíduos participantes da proposta, bem como os conteúdos matemáticos que são trabalhados a partir de uma proposta de Modelagem Matemática. 
Ainda, diferentemente de Barbosa, que não evidencia etapas para o desenvolvimento de uma proposta de Modelagem, Burak propõe cinco delas: "1) escolha de um tema; 2) pesquisa exploratória; 3) levantamento do (s) problema (s); 4) resolução dos problemas e desenvolvimento dos conteúdos no contexto do tema; 5) análise crítica da (s) solução (ões)" (Ibidem, p.89). É importante salientar que Burak (2012) esclarece que as etapas sugeridas por ele não podem ser vistas como passos rígidos e estanques. É possível haver alterações, já que elas devem ser priorizadas de maneira natural ao longo do trabalho com Modelagem.

A Modelagem Matemática, com o passar do tempo, foi se reinventando e, como vimos, atualmente, não existe um único modo de com ela se operar. Nesse sentido, trazemos as contribuições de Barbosa (2001), que, segundo ele, no Brasil, essa tendência está ligada à noção de trabalho de projeto em que os alunos são organizados em grupos e cada qual desenvolve uma investigação por meio da Matemática, tendo como foco seu tema de interesse e, ao mesmo tempo, contando com o acompanhamento e auxílio do professor.

Em seus estudos, Barbosa também aponta inúmeros registros de práticas pedagógicas centradas na Modelagem Matemática voltadas à investigação e problematização de questões sociais. Barbosa (2004) enfatiza uma delas em que disponibilizou uma tabela de preços em relação a quatro planos de companhias distintas que ofereciam serviços de internet. Nela, constavam o valor da assinatura mensal, o tempo de acesso incluído e o valor por tempo adicional (hora). A partir desses dados, coube aos alunos optarem pela companhia que continha o melhor plano. Em um segundo momento, o autor explica que partiu de um questionamento por meio do qual os próprios discentes enfrentaram o desafio de buscar dados relativos à questão, para que, posteriormente, a situação-problema fosse solucionada. A indagação surgiu da seguinte problematização: "Quanto custa ter acesso à internet?" (BARBOSA, 2004, p. 6).

Barbosa idealiza a corrente sociocrítica de Modelagem Matemática que dispõe, em sua íntegra, a preocupação com o conhecimento reflexivo e com a função social. Assim sendo, Barbosa (2001, p.4) aponta que

As atividades de Modelagem são consideradas como oportunidades para explorar os papéis que a matemática desenvolve na sociedade contemporânea. Nem matemática nem Modelagem são "fins", mas sim "meios" para questionar a realidade vivida. Isso não significa que os alunos possam desenvolver complexas análises sobre a matemática no mundo social, mas que Modelagem possui o potencial de gerar algum nível de crítica. É pertinente sublinhar que necessariamente os alunos não transitam para a dimensão do conhecimento reflexivo, de modo que o professor possui grande responsabilidade para tal (BARBOSA, 2001, p.4).

Logo, por meio da corrente sociocrítica, percebe-se que a função social da Matemática é desempenhada de fato, já que ela parte do contexto no qual o aluno e a escola se encontram e, através desse panorama, a citada disciplina se insere para responder a questões práticas do cotidiano. Há um diálogo entre teoria e prática e, nesse jogo, o importante não é o aluno construir modelos matemáticos e verificar sua aplicabilidade na situação-problema elencada, nem como estudar a Matemática por intermédio de outras áreas do conhecimento. A preocupação maior está em utilizá-la com o propósito de responder às dúvidas, às problemáticas de um dado contexto social, ampliando a capacidade de refletir criticamente nossas próprias formas de ver, estar e viver. 
Barbosa (2001) também aposta em um currículo diferenciado, que disponha de múltiplas possibilidades educativas, que seja o contrário das correntes pragmática e científica. Não busca tirar ou acrescentar conteúdos ao currículo da Matemática ou, ainda, gerar discussões sobre o que pode ser considerado "melhor", útil ou não. Desse modo, o autor aponta que

[...] não advogamos um currículo baseado nem somente nas aplicações nem somente na estrutura da matemática. Julgamos que a educação matemática deve envolver todas as instâncias implicadas no conhecimento matemático. Modelagem é uma delas. É necessária, mas não suficiente (BARBOSA, 2001, p.5).

Em termos de procedimentos metodológicos, Barbosa (2001, p.8) recusa "a ideia de associar Modelagem exclusivamente à modalidade de projetos. Outros tipos de atividades de Modelagem, que demandam menos tempo e são mais simplificadas, também podem ser consideradas". Nesse sentido, o autor nos apresenta três configurações distintas para a abordagem da Modelagem Matemática, de modo que cada uma delas é vista como um caso.

Segundo Barbosa (2001), no caso 1, o professor é quem propõe à turma a situaçãoproblema, bem como todos os dados necessários à sua resolução. Aos alunos cabe a responsabilidade de resolverem a problemática. No caso 2, o docente dispõe como ponto de partida para a investigação o apontamento da situação-problema, com a temática voltada às mais diferentes áreas do conhecimento. Os estudantes são desafiados a buscarem todos os dados necessários à resolução do problema em questão, fato que, certamente, estender-se-á por mais aulas e para o qual poderão ser utilizados diferentes suportes de pesquisa locais e até mesmo profissionais de diferentes áreas afins. Já o caso 3 exige maior autonomia por parte do discente e flexibilidade e interação/mediação do professor, onde "a partir de temas não- matemáticos, os alunos formulam e resolvem problemas. Eles também são responsáveis pela coleta de informações e simplificação das situações-problema. É via do trabalho de projetos" (BARBOSA, 2001, p.9).

Podemos observar que, à medida que a autonomia dos alunos em cada caso aumenta, a centralização no professor diminui, de forma que a aprendizagem começa a exigir mais daqueles. Mesmo assim, a atuação deste é essencial, mesmo que tenha tomado outra forma. Ele passa a ser um copartícipe do conhecimento. Ambos - professor e aluno aprendem ao mesmo tempo, sendo os dois coautores da aprendizagem.

Existem diferentes conceitos e formas de pensar a Modelagem Matemática e como esta acontece, tendo em vista o seu procedimento metodológico. Barbosa (2004) se posiciona de uma forma que nos faz pensar que ela vai muito além da aplicação. Mesmo sabendo que, em sua história, foi influenciada pelos pesquisadores da Matemática Aplicada, não podemos resumi-la somente a essa perspectiva. Sendo assim, Barbosa (2004) admite que

Muitas vezes, Modelagem é conceituada, em termos genéricos, como a aplicação de matemática em outras áreas do conhecimento, o que, a meu ver, é uma limitação teórica. Dessa forma, Modelagem é um grande 'guarda-chuva', onde cabe quase tudo. Com isso, não quero dizer que exista a necessidade de se ter fronteiras claras, mas de se ter maior clareza sobre o que chamamos de Modelagem (BARBOSA, 2004, p 1-2). 
Em virtude desse apontamento, podemos observar as convergências e divergências de Barbosa e de Biembengut e Hein em relação à Modelagem Matemática. As concepções defendidas pelos citados autores nos levam a concluir que ambas são desenvolvidas a partir de uma situação/tema através do qual se desenvolvem questões a serem respondidas. É evidente que a pesquisa também acontece, mas a diferenciação de fato está no restante do procedimento. A proposta apontada por Biembengut e Hein (2005) está fortemente ligada a conteúdos matemáticos e à sua utilização por meio dos modelos matemáticos, enquanto que a corrente sociocrítica, defendida por Barbosa, tem em vista a Modelagem Matemática como um recurso para responder a dúvidas e até mesmo problemas sociais, valendo-se também do uso da Matemática, mas não de modo tão sistemático e metódico. Como apontam Silva, Barbosa e Oliveira (2013, p.48),

As discussões sobre modelagem matemática têm sido crescentes na comunidade de educação matemática como uma possibilidade de gerar investigações de problemas com referência na realidade na sala de aula de matemática (Barbosa, 2007; Oliveira, 2007; Cargnin-Stieler; Bisognin, 2011). Por modelagem, compreendemos como um ambiente de aprendizagem, no qual os estudantes são convidados a investigar, utilizando a matemática, situações com referência na realidade (Barbosa, 2007). Em vista disso, argumentamos que, ao trabalhar com modelagem, os estudantes são desafiados a assumirem uma postura crítica e participativa com vistas ao exercício da cidadania (Barbosa, 2007). A expressão "ambiente de aprendizagem" é utilizada por Skovsmose (2000) para se referir às condições proporcionadas aos estudantes para desenvolverem suas ações (SILVA; BARBOSA; OLIVEIRA, 2013, p. 48).

Por meio dessa citação, podemos elencar uma série de fatores que contribuem para a qualificação do Ensino de Matemática tendo em vista a perspectiva sociocrítica da Modelagem Matemática. Assim, iniciaremos a discussão sobre o fato de o aluno estar engajado na investigação, onde, por meio de pesquisas a diversas fontes e materiais, far-seá o levantamento de dados sobre a temática, assim como o aprofundamento do tema a ser estudado. A investigação não culmina na simples pesquisa, mas na inter-relação de temas relacionados à realidade do aluno, tanto em sala de aula como em seu âmbito social. Dessa forma, ela provoca o aluno a refletir sobre aspectos sociais, tornando-o capaz de analisar e se posicionar de maneira crítica perante as situações cotidianas.

A Modelagem Matemática, consoante com a corrente sociocrítica elaborada por Jonei C. Barbosa, tem como principal objetivo possibilitar que a Matemática cumpra seu papel social, permitindo que o aluno atue como um cidadão participativo (ativo). Muitas vezes, por desconhecer algum assunto ou não saber vincular o conhecimento matemático ao tema em questão, ele passa a aceitar certas decisões sem questionar a veracidade destas, o que faz dele um sujeito passivo. Sendo assim, Barbosa (2011) contribui com essa visão, destacando que

A modelagem matemática pode ter como propósito desenvolver atividades que ofereçam subsídios aos alunos na compreensão de como a matemática é utilizada nas práticas sociais (BARBOSA, 2001). Essa perspectiva de modelagem - denominada sócio-crítica por Barbosa (2003) - enfatiza a atuação do aluno na sociedade, analisando o papel da matemática nos debates sociais (SILVA; BARBOSA, 2011, p. 198). 
De fato, o propósito da Modelagem Matemática não é o de mostrar que a Matemática está em todos os lugares, mas como e quando podemos usá-la para problematizar questões sociais ou até mesmo situações-problema sobre os quais se tenha dúvidas e curiosidades. De modo simplificado, Barbosa (2004, p. 2) salienta que, para inserir a Modelagem Matemática no currículo, levando em consideração seus benefícios à Educação Matemática, "em geral, são apresentados cinco argumentos: motivação, facilitação da aprendizagem, preparação para utilizar a matemática em diferentes áreas, desenvolvimento de habilidades gerais de exploração e compreensão do papel sociocultural da matemática". Sobretudo, em sua bibliografia, o autor esclarece que, dentre as situações, a compreensão do papel sociocultural é a mais importante.

A inovação no Ensino da Matemática é outro aspecto que vale a pena ser destacado, pois a Modelagem Matemática quebra toda e qualquer estrutura linear de conhecimento e de organização. Não há previsão, pelo menos no início, do que será estudado, dos termos matemáticos que serão utilizados, já que essa proposta visa a uma construção coletiva e colaborativa entre aluno e professor. Para além da inovação, também é possível trabalhar em uma mesma turma várias temáticas e encaminhamentos diversos quanto ao uso da Matemática. Novamente, a estrutura tradicional, vista sob o olhar de que todos devem aprender a mesma coisa ao mesmo tempo, é rompida, mas sim de acordo com seu interesse de pesquisa, principalmente no caso 3. Neste, a própria situaçãoproblema/problematização é construída pelo grupo de estudantes, assim como o levantamento de dados e resolução, respeitando o tempo de aprendizagem de cada discente.

\section{Da metodologia de pesquisa e da docência}

Durante o primeiro semestre do ano de dois mil de quinze, foi desenvolvida uma prática pedagógica investigativa em uma escola municipal do Vale do Taquari, com uma turma de $5^{\circ}$ ano do Ensino Fundamental. A referida prática esteve centrada na concepção de Modelagem Matemática defendida por Jonei Cerqueira Barbosa, partindo de uma proposta de Modelagem Matemática de caso 1. Esta foi pensada, construída e projetada somente após o conhecimento dos alunos e seus interesses de pesquisa em relação ao trabalho de Modelagem Matemática. Embora tivesse sido traçado um planejamento prévio em relação aos seis encontros, em cada prática, o plano de ação sofria alterações.

Nos meses de abril e maio, foram realizados, às terças e quintas-feiras, seis encontros semanais com os alunos, cuja duração foi de quatro horas / aula cada um. Apenas o último, que se caracterizou por uma roda de conversa sobre os demais, ocorreu em uma quarta-feira e envolveu apenas uma hora. Nesse dia, os alunos foram estimulados a relatarem suas percepções em relação à proposta de trabalho desenvolvida com a turma sob a perspectiva da Modelagem Matemática. O diálogo foi gravado e conduzido por questões norteadoras mediadas pela professora investigadora, as quais foram pensadas e elaboradas ao longo da prática pedagógica investigativa.

Esse momento teve o propósito de fazer uma avaliação da prática pedagógica investigativa, apontar as construções individuais e coletivas alcançadas ao longo da proposta, facilidades, dificuldades e reflexões acerca do uso da Matemática para resolver situações cotidianas. Os encontros partiram da problemática inicial relativa à natureza dos 
investimentos necessários à construção da quadra poliesportiva coberta da escola, interesse constantemente demonstrado pela turma durante o desenvolvimento das atividades.

No primeiro encontro, os alunos foram instigados a relatarem tudo o que sabiam sobre a quadra poliesportiva coberta da escola, como uma explosão de ideias que possibilitasse inúmeros caminhos para a conversa. Frente a essa situação, a professora pesquisadora lançou alguns questionamentos, levando a turma a pensar sobre a natureza dos investimentos realizados no citado empreendimento. Ao longo do diálogo, as discussões e indagações foram realizadas de maneira natural, o que levou ao entrecruzamento de opiniões e informações trazidas pelos próprios discentes.

No mesmo dia, fizemos a leitura de uma reportagem sobre a construção da quadra a fim de buscar conhecimentos relativos a valores investidos e demais dados que pudessem ser discutidos naquela ocasião. Por fim, em duplas, a turma refletiu sobre questões pertinentes aos impostos que conheciam, atitudes prejudiciais à sua coleta, bens públicos municipais e atitudes que devemos ter para com os bens públicos.

Já no segundo encontro, a prática contou com a presença do contador municipal, que esclareceu algumas dúvidas relativas à construção da quadra, bem como impostos e outras taxas que a turma apontava de forma espontânea. Também ocorreu o resgate de conceitos que já haviam sido estudados na aula anterior, confrontando todas as respostas elaboradas pelos alunos em Datashow, sem identificação de nomes e letra, já que foi digitado pela professora investigadora. Esse momento de aprendizagem levou os estudantes à realização de um levantamento de dados sobre todos os impostos que conheciam, ocasião em que também aconteceu a diferenciação de bem e de local público, fato que os confundia. Além disso, abordaram-se, de modo bastante crítico, as ações que têm prejudicado a coleta de impostos - sonegação, desvio de dinheiro, pirataria, contrabando e não solicitação de nota fiscal.

No terceiro encontro, a aula iniciou com um trabalho de análise em grupos. Para isso, a turma se organizou em três grandes grupos, com a função de observar, ler, comparar e manusear notas fiscais diversas, a fim de realizar um levantamento de dados das informações que se assemelhavam entre os citados documentos. Finda a análise, cada equipe relatou suas observações e, em seguida, coletivamente, explanou, em um quadro, os itens que deveriam constar ( dados/informações) em uma nota fiscal.

Assim, aproveitando o material que estava sendo manuseado/explorado, os alunos foram incentivados a buscarem, nas notas fiscais, os valores aproximados de tributos arrecadados na compra. Nesse momento, a professora pesquisadora realizou uma breve explanação sobre a Lei 12.741/2012, que, desde junho de 2013, exige que todo documento fiscal ou equivalente emitido contenha a informação do valor aproximado correspondente à totalidade dos tributos federais, estaduais e municipais, cuja incidência influencia na formação dos respectivos preços de venda. Esse fato nos levou a desenvolver um trabalho matemático voltado à porcentagem por meio de cálculos aproximados, ocasião em que apresentamos desafios com o intuito de conduzir a turma ao cálculo do valor em dinheiro destinado aos impostos referentes a produtos (todas as informações utilizadas sempre foram verídicas).

No quarto encontro, a turma desenvolveu problemas matemáticos envolvendo a análise de notas fiscais (com alguns dados ocultados) e, dessa forma, os alunos calcularam o valor total gasto na compra, o destinado aos impostos e caso estes não fizessem parte da 
aquisição. Nos cálculos, foram utilizadas aproximações, levando em conta a porcentagem associada às frações $-50 \%-1 / 2,25 \%-1 / 4,10 \%-1 / 10$.

No quinto encontro, as atividades iniciaram em frente à escola, onde encontrarmos uma placa que especificava alguns dados referentes à construção da quadra poliesportiva coberta. Nessa placa, foi possível avistar informações pertinentes ao valor total investido na obra (R\$ 279.352,59), comunidade, município, estado onde ela ocorreu, agentes participantes do investimento (Governo Federal e Município), início - 4 de abril de 2014 - e término - 4 de setembro de 2014.

Os alunos desenvolveram seus registros no caderno e, ao retornar à sala, houve uma discussão sobre os dados encontrados e a comparação destes com as situações reais, ou seja, análise do que estava escrito na placa e que não condizia com a realidade. O fato se deveu à data do término da quadra e à comunidade. Na verdade, o nome desta não havia sido especificado, simplesmente repetiu-se o nome do município.

$\mathrm{Na}$ sequência, os alunos receberam uma folha com as atividades que remetiam a pensar sobre a quantidade de salários necessários para se atingir o valor investido na quadra e, posteriormente, transformá-lo em meses e anos. Também refletimos sobre o tempo utilizado para a construção até esse momento, estabelecendo uma comparação com a previsão que constava no projeto.

Por fim, no último encontro, resgatamos todas as atividades desenvolvidas ao longo de nossos estudos, além de uma avaliação das aprendizagens conquistadas, facilidades e dificuldades.

\section{Acerca dos resultados}

Ao longo dos encontros, ficou evidente que os alunos pouco escreveram, de maneira argumentativa, sobre a metodologia desenvolvida. Aparentemente, julgavam ser suficiente desenvolver um cálculo e, como resposta, colocar o resultado. Devido a isso, muitas vezes, ocorreram usos inadequados de números/valores apresentados na questão, pois a operação matemática utilizada não condizia com a sua problematização. Quando solicitados a refletirem sobre a forma como desenvolveram o problema, demonstravam enormes dificuldades em iniciar e produzir um texto escrito.

Nesses momentos, sugeria-se que contassem como haviam pensado em desenvolver o problema e por quê. À medida que colocavam à professora pesquisadora o que tencionavam enunciar, percebiam o que de fato deveriam escrever. Entretanto, alguns não atentavam ao que estavam registrando e, como não possuíam o hábito da releitura, muitos erros passavam-Ihes despercebidos. Nesse sentido, cabe destacar as ideias de Knijnik e Wanderer (2004?), quando afirmam que alguns modos de produzir conhecimentos são classificados como melhores do que outros. Em especial, no caso aqui examinado, poderíamos inferir que os próprios alunos entendiam que o cálculo a ser apresentado à docente teria validade se fosse devidamente anotado. Assim,

[...] Os modos de produzir conhecimentos, compreender o mundo e dar significado às experiências da vida cotidiana de outros povos e culturas (como, por exemplo, os não europeus, não brancos, não urbanos) são considerados como não ciência, como não-conhecimento. Nesta operação etnocêntrica, tais saberes acabam sendo desvalorizados, não porque sejam, do ponto de vista epistemológico inferiores, mas, antes de 
tudo, porque não se constituem na produção daqueles que, na sociedade ocidental, são considerados como os que podem/devem/são capazes de produzir ciência (KNIJNIK; WANDERER, 2004, p.2).

Embora considerassem a relevância do cálculo, os alunos mostraram outros modos de pensar matematicamente. Esse fato nos remete aos discursos que, muitas vezes, ouvimos de nossos professores de Matemática sobre a importância de analisar o processo e não apenas o resultado. Realmente, por mais que este seja único, há diferentes modos de alcançá-lo. Isto posto, apresentamos contribuições apontadas por D'Ambrósio, que salienta:

O raciocínio qualitativo é essencial para se chegar a uma nova organização da sociedade, pois permite exercer crítica e análise do mundo em que vivemos. Deve, sem qualquer hesitação, ser incorporado nos sistemas educacionais. Essa incorporação se dá introduzindo nos programas, em todos os níveis de escolaridade, estatística, probabilidades, programação, modelagem, fuzzies, fractais e outras áreas novas emergentes na ciência atual (D'AMBRÓSIO, 2013, p.44).

É possível refletir sobre isso tendo por referência duas atividades propostas à turma. A primeira apresentada no quarto encontro; a segunda, no quinto. As tarefas desenvolvidas pelos alunos $\mathrm{H}$ e D retratam a forma única de cada aluno raciocinar matematicamente em uma mesma problemática: chegar ao valor total da compra descrita na nota fiscal. H desenvolveu um agrupamento de valores onde o cálculo foi desenvolvido por etapas, somando sempre de dois em dois produtos. No final, reuniu todos os valores das adições em um único cálculo para obter o resultado. Certamente, alguém poderia afirmar que todo esse processo seria uma perda de tempo, já que ele poderia ter desenvolvido um único cálculo. No entanto, a estratégia adotada permite menos erros, uma vez que as adições são realizadas em parcelas menores.
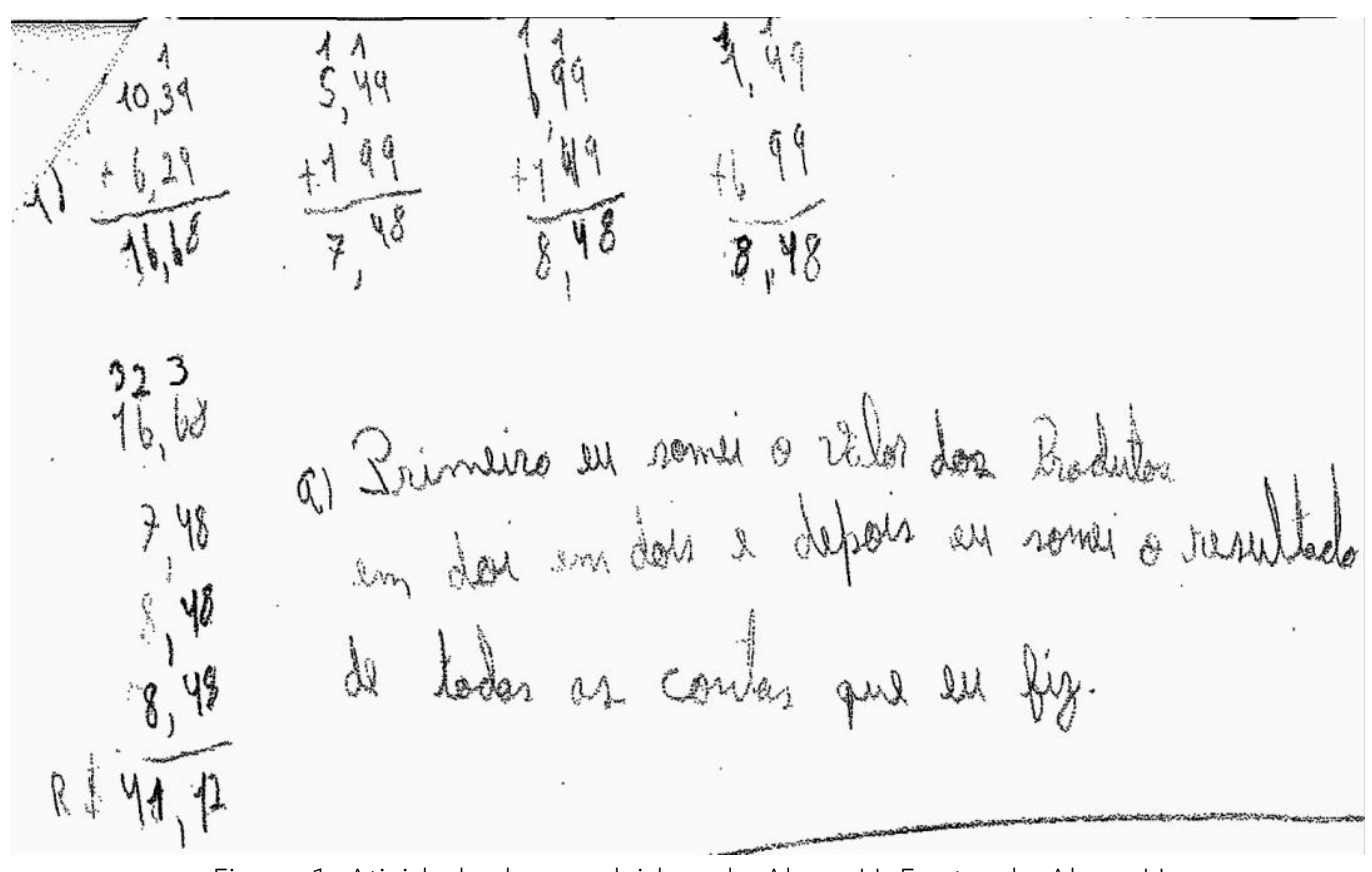

Figura 1: Atividade desenvolvida pelo Aluno $\mathrm{H}$. Fonte: do Aluno $\mathrm{H}$ 
Já D organizou o cálculo em duas etapas: primeiro calculou os centavos; posteriormente, os reais; por último, reuniu os resultados (centavos e reais) em um único cálculo, chegando ao valor total da compra. Ressaltamos que não havíamos visto essa estratégia em momentos anteriores, chegando, inclusive, a julgá-la mais difícil, por exigir que o aluno atente quanto à posição da vírgula, uma vez que envolve dinheiro.

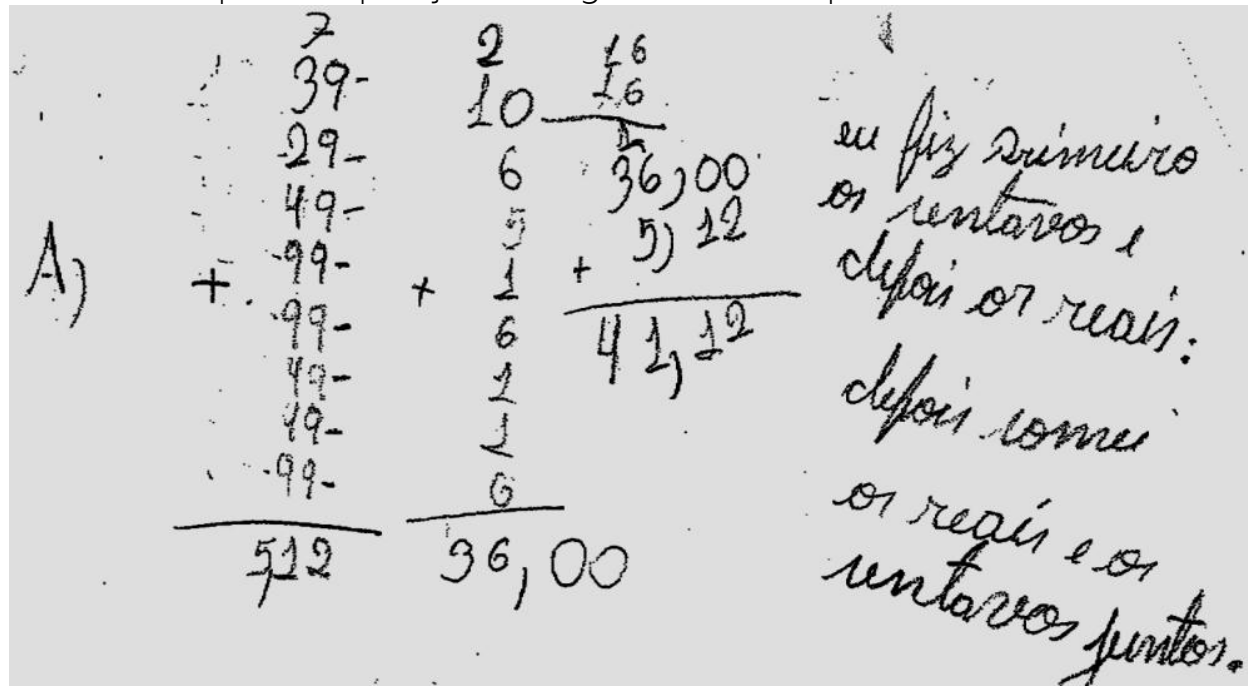

Figura 2: Atividade desenvolvida pelo Aluno D. Fonte: do Aluno D

No quinto encontro, aconteceu algo semelhante que também nos fez refletir sobre as diferentes estratégias adotadas pelos alunos frente a um problema matemático. A questão se referia ao cálculo de quantos salários-mínimos uma pessoa precisaria juntar para atingir o valor investido na quadra. Sabendo-se que o piso nacional era de setecentos e oitenta e oito reais ( $R \$ 788,00)$, e a soma investida na quadra correspondia a duzentos e setenta e nove mil, trezentos e cinquenta e dois reais e cinquenta e nove centavos ( $R \$ 279.352,59$ ), poderíamos chegar ao valor aproximado de 354 vezes, ou 50 salários-mínimos.

Quando criamos e propusemos essa questão, tínhamos a certeza de que a turma desenvolveria um cálculo de divisão. Para nossa surpresa, surgiram inúmeras tentativas de cálculos pela multiplicação e, ainda, um aluno optou pela adição (788+788). Tentamos dissuadi-lo, questionando-o sobre o tamanho do problema que enfrentaria e mostrandoIhe outras possíveis maneiras de chegar ao resultado. No entanto, ele se manteve irredutível, passando boa parte da aula desenvolvendo seus inúmeros cálculos que não the permitiram chegar a uma conclusão plausível.

Outro fato que mereceu nossa atenção se refere à dificuldade dos alunos de lidar com números maiores, já que, nesse caso, estávamos trabalhando com um elevado ( $R$ \$ 279.352,59). Logo, era fundamental discutirmos a quantificação e a comparação do citado número com o outro (788). Na correção, a professora pesquisadora priorizou esse momento, ressaltando que, através da leitura do número, era possível observar, instantaneamente, que seriam necessários mais de 279 salários e, assim, desenvolver cálculos de adição e multiplicação, mas que fossem planejados e não desenvolvidos de maneira aleatória.

Ademais, pensamos ser indispensável apresentamos outras estratégias utilizadas por alguns alunos referentes à mesma questão. Um dos grupos optou por desenvolver a proposta de atividade por meio de cálculos de multiplicação. Segundo relato de vários deles, inicialmente empregaram números menores; porém, logo perceberam que os encontrados estavam longe de chegar a $R \$ 279.352,59$, o que os levou a utilizarem os 
maiores. S declarou que teria até desenvolvido a multiplicação 788 X 788, mas logo percebeu que o valor obtido ultrapassou muito o que buscava, chegando a ser mais do que o dobro. A partir dali, refletindo sobre o processo que havia realizado, passou a desenvolver cálculos mais conscientes e, assim, chegou ao resultado aproximado - 354 vezes. Segundo D’Ambrósio,

As ideias matemáticas, particularmente comparar, classificar, quantificar, medir, explicar, generalizar, inferir e, de algum modo, avaliar, são formas de pensar, presentes em toda espécie humana. A atenção dos cientistas da cognição vem sendo crescentemente dirigida a essa característica da espécie (D'AMBRÓSIO, 2013, p.31).

Levando em conta que um dos objetivos deste estudo esteve vinculado à promoção da capacidade de fazer uso de conhecimentos vinculados à disciplina de Matemática em outras áreas de conhecimentos e em situações cotidianas, e outro consistia em avaliar as contribuições da prática pedagógica na reflexão crítica do aluno frente às questões sociais, refletimos que, de fato, as metas foram atingidas. Como pode ser visto através da metodologia utilizada, é visível que, durante os encontros, o fator social esteve muito presente. Inúmeras rodas de conversas, debates e discussões possibilitaram o crescimento da turma frente aos aspectos sociais abordados ao longo das aulas.

Logo no primeiro encontro, conseguimos nos afastar da visão ingênua, generalizada e inconsciente que, muitas vezes, demonstramos em relação aos bens públicos construídos por meio de recursos públicos. Burak e Aragão (2012, p.14), salientam que "[...] Uma educação de qualidade é aquela que leva o educando à libertação de ingenuidades que o fazem permanecer na miséria física e intelectual". Com base em Burak e Aragão, resgatamos as falas dos alunos (que foram gravadas), os quais, no encontro realizado no dia 14 de abril, lançaram suas contribuições, relatando o que sabiam sobre a origem do dinheiro investido na quadra poliesportiva da escola:

\section{(...)}

Professora investigadora - Da onde eles levantaram verba? (referindo-se à origem do dinheiro investido na quadra poliesportiva).

Aluno J - Do imposto.

Aluna P - Da escola.

Aluno M - Com o dinheiro da escola.

Aluna $\mathrm{G}$ - Dos alunos.

Aluno N - Do governo.

Aluno D - Do dinheiro da merenda.

(...)

Aluna A - Do dinheiro das rifas, do bingo, e das outras festas que...e das merendas que têm pra vender na hora do recreio. Tudo os alunos pagam pra ajudar a escola.

Aluna B - E também do chá de família.

(...)

Professora investigadora - Mais alguém tem alguma ideia diferente pessoal? Da onde surgiu este dinheiro?

Aluno J - Dos impostos.

(...)

Aluno D - O dinheiro vem lá do governo. O governo dá pra prefeitura, e a prefeitura dá pra gente. 
(...)

Professora investigadora - Pessoal, o dinheiro vem do governo?

Aluno J - Não!

Aluno F - A maioria...eu acho que a maioria vem.

(...)

Professora investigadora - Mas pessoal, o governo tira este dinheiro de onde?

(...)

Aluno J - Dos impostos que a gente paga.

(..)

A partir desse diálogo, foi possível detectar uma primeira visão dos alunos sobre a origem dos investimentos projetados na quadra. Podemos perceber que, logo de início, o aluno J trouxe como contribuição o fato de o dinheiro ter sido gerado através dos impostos. Ao longo de toda a conversação, mostrou sua convicção, enquanto que os demais refletiam sobre ações realizadas pela escola para angariar fundos e a ideia de que o governo é quem teria oferecido o dinheiro. À medida que a conversa foi se desenvolvendo, muitas constatações puderam ser realizadas e, principalmente, a desconstrução da ideia de que o governo "deu".

Uma de nossas discussões em sala de aula nos reportou às contribuições de Burak e Aragão (2012, p.17-18), que desenvolvem uma crítica relativa ao Ensino de Matemática e sobre as possibilidades de ação que temos à nossa disposição quando se trata do desenvolvimento de um trabalho pedagógico com um grupo de alunos. Proporcionar o desenvolvimento de uma atividade partindo do que o estudante já sabe, ouviu falar, ou, de alguma forma, estabeleça conexões com situações que ele vivenciou anteriormente faz com que as discussões realizadas em sala de aula tenham significado.

A educação escolar brasileira persiste em continuar a solicitar, de modo geral, dos estudantes o uso excessivo da memória, não só no que tange ao ensino da Matemática pela repetição mecânica de algoritmos, mas também pela padronização estéril da resolução de problemas, pela descontextualização de situaç̃̃es sociais e pela mera aplicação de fórmulas. É preciso ter clareza de que o tipo de aprendizagem que se torna imprescindível para o aluno é compreender efetivamente a Matemática é de natureza tal que, se no contexto escolar de ensino e de aprendizagem não se partir do conhecimento já adquirido e do interesse do próprio estudante, se não se levar em conta sua história e o que ele já sabe, o conhecimento que se quer aprendido não se estabelece em termos usualmente dissociados. Isto quer dizer que a aprendizagem que possibilita tornar o estudante cidadão implica a possibilidade de este vir a atribuir sentidos e significados ao que se aprende, em função da sua experiência de mundo (BURAK, ARAGÃO, 2012, p.17-18).

Durante os encontros, priorizamos a reflexão sobre a necessidade de zelarmos pelos bens públicos, bem como a exigência de notas fiscais em qualquer compra. Por meio destas, desenvolvemos grande parte de nossas atividades, motivo pelo qual acreditamos ter sido o elemento primordial do nosso trabalho. Comentários sobre o que caracterizaria uma nota fiscal e estabelecimentos do município que costumavam não a emitir foram recorrentes em nossas aulas. Com isso, destacamos que a reivindicação de tal documento é uma garantia maior de que realmente o imposto seja arrecadado e enviado aos cofres 
públicos. Os comerciantes que fornecem a "notinha" apenas quando esta é solicitada pelo comprador, provavelmente, guardem o bloco de notas fiscais em algum lugar para fins exclusivos de fiscalização. Portanto, é dever do comprador insistir pelo recebimento.

Nesse sentido, retomamos algumas considerações de Barbosa (2004, p.3), que aponta que a Modelagem, para ele, "é um ambiente de aprendizagem no qual os alunos são convidados a problematizar e investigar, por meio da Matemática, situações com referência na realidade". De fato, com esse trabalho, as aulas foram se constituindo de tal forma que propiciaram aos alunos a prática de reflexão sobre seu contexto social.

A Matemática foi utilizada como meio de reflexão sobre a quantidade de impostos que pagamos sobre os produtos e outras temáticas exploradas em sala de aula, como a análise do valor total investido na quadra em comparação com o salário mínimo nacional. A porcentagem foi algo que, inicialmente, "assustou" os alunos que, de certo modo, não sabiam do que se tratava. Porém, através dos seus próprios relatos, com o passar do tempo, as atividades se tornaram "mais fáceis".

A Modelagem Matemática vai além do fazer Matemática para simplesmente aprimorar uma técnica, uma fórmula. Ela possibilita problematizar situações do dia a dia, levando o aluno a refletir sobre suas próprias condutas, tornando-o mais crítico em relação a questões sociais. Nesse sentido, concluímos esta sessão trazendo uma contribuição Barbosa (2004, p.3), que confirma o que vínhamos dizendo até então: "creio que Modelagem pode potencializar a intervenção das pessoas nos debates e nas tomadas de decisões sociais que envolvem aplicações da Matemática, o que me parece ser uma contribuição para alargar as possibilidades de construção e consolidação de sociedades democráticas".

\section{Considerações finais}

Foi extremamente significativo poder trabalhar a Modelagem Matemática como estratégia de ensino, já que permitiu aos alunos aprenderem não apenas conhecimentos matemáticos, mas os que faziam/ fazem parte de seu cotidiano, levando-os a refletir sobre suas atitudes, escolhas, formas de viver. Uma Matemática necessária à vida. Acreditamos que, nas escolas, muitas vezes, não se tem mostrado como, onde e quando o conteúdo matemático pode ser utilizado. Embora nem sempre seja possível estabelecer essa relação, traçar uma ponte entre os saberes e a realidade sempre que o assunto permitir representa um grande avanço.

Ao resgatarmos uma problemática de toda a pesquisa que se situa na questão "Quais são as possibilidades e limitações de uma prática pedagógica investigativa efetivada em uma turma de $5^{\circ}$ ano do Ensino Fundamental, tendo como aportes teóricos estudos do campo da Modelagem Matemática"?, desencadeamos uma breve síntese que se direciona às possibilidades da mencionada prática:

- diálogo entre as diferentes áreas de conhecimento nas aulas de Matemática, favorecendo a aprendizagem do aluno dos Anos Iniciais que trabalha o conhecimento de modo integrado até o $3^{\circ}$ ano, e, a partir do $4^{\circ}$ ano, passa a estudar as disciplinas de modo separado, por meio de horários, não significando a inexistência de conexão entre elas;

- ponte entre conhecimentos matemáticos/ escolares e a realidade, fazendo com que o aluno tome uma postura mais crítica frente a questões sociais; 
- reinvenção da dinâmica de aula adotada pelo professor ao desenvolver um trabalho de Modelagem Matemática, que necessita ser colaborativo, ou seja, ser pensado a partir do interesse aluno e, posteriormente, inserir conteúdos matemáticos e não matemáticos;

- repensar a postura do professor e do aluno;

Refletindo sobre as limitações de uma prática de Modelagem Matemática no $5^{\circ}$ ano do Ensino Fundamental, elencamos apenas um fator que, de fato, foi possível presenciar, mas que, ao mesmo tempo, não pode ser tomado como parâmetro e parte do processo de futuras práticas pedagógicas envolvendo a Modelagem Matemática em experimentações vindouras. Assim, pensamos que fatos ocorridos nesta prática poderão não se repetir em outras situações, ou, ainda, não produzir os mesmos efeitos.

Inicialmente, destacamos a resistência dos alunos diante de algumas propostas que necessitavam de maior reflexão, argumentação e envolvimento de sua parte. Foi algo que, de certa forma, pode não ter sido comum nas aulas de Matemática experienciadas por eles anteriormente. Havia momentos em que alguns não participavam dos encontros; sua presença era apenas física. Incialmente, tal fato nos causou preocupação e certa decepção; entretanto, lembramos que a proposta sociocrítica de Modelagem Matemática não visa atingir a todos da mesma forma, mas a cada um de maneira diferenciada, causando diferentes reações e saberes.

Sobre os objetivos da pesquisa, acreditamos tê-los atingido. Elaboramos e desenvolvemos a prática pedagógica em conjunto com os alunos; avaliamos as suas contribuições de acordo com as reflexões sobre questões sociais; utilizamos diferentes conhecimentos matemáticos, não matemáticos e do cotidiano dos participantes ao longo da prática pedagógica investigativa. Dessa forma, esperamos ter contribuído para futuras pesquisas no campo da Modelagem Matemática nos Anos Iniciais do Ensino Fundamental.

Enfatizamos a importância deste estudo por termos a certeza de que ele possibilitou inúmeras reflexões, experiências, saberes que serão levados adiante. Finalizamos com a seguinte reflexão:

[...] o porquê de se ensinar Matemática? E o porquê se ensinar mediado pela Modelagem? Entendemos que a concepção de "homem" que se pretende formar para enfrentar os desafios do século XXI é uma questão que tem a ver com a forma de se ensinar e com o que se ambiciona com isso. Essas questões invocam algumas respostas. Não pretendemos formar sujeitos sem determinação, sem ideias próprias, sem capacidade de argumentar e dialogar sobre uma situação, não pretendemos formar um sujeito incapaz de decidir por si, sem possibilidade de antever uma situação, sem noção do global. Ao contrário, intencionamos formar um cidadão que desenvolva a autonomia e seja crítico, capaz de trabalhar em grupo, capaz de tomar decisões diante das situações do cotidiano, da sua vida familiar, da sua vida profissional ou de sua condição de cidadão, um sujeito capaz de promover transformações em sua comunidade (BURAK, ARAGÃO, 2012, p.85). 


\section{Referências}

BARBOSA, J. C. Modelagem na Educação Matemática: contribuições para o debate teórico. In: REUNIÃO ANUAL DA ANPED, 24, 2001, Caxambu. Anais... Rio Janeiro: ANPED, 2001. 1 CD-ROM. Disponível em: <http://www.ufrgs.br/espmat/disciplinas/funcoes_modelagem/ modulo_I/modelagem_barbosa.pdf> Acesso em: agosto de 2014.

BARBOSA, Jonei Cerqueira. Modelagem Matemática na sala de aula. In: VIII Encontro Nacional de Educação Matemática - Minicurso GT 10 - Modelagem Matemática. Anais... Recife: Universidade Federal de Pernambuco, 2004. Disponível em <http://www.sbembrasil.org.br/files/viii/pdf/10/MC86136755572.pdf> Acesso em: agosto de 2014.

BIEMBENGUT, Maria Salett; HEIN, Nelson. Modelagem matemática no ensino. $4^{a}$ ed. São Paulo: Contexto, 2005.

BURAK, Dionísio; ARAGÃO, Rosália Maria Ribeiro de. A modelagem matemática e relações com a aprendizagem significativa. $1^{\text {a }}$ ed. Curitiba, PR: CVR, 2012.

D'AMBRÓSIO, Ubiratan. Etnomatemática: Elo entre as tradições e a modernidade. $5^{a}$ edição. Belo Horizonte: Autêntica Editora, 2013.

KNIJNIK, Gelsa; WANDERER, Fernanda. Educação Matemática e oralidade: um estudo sobre a cultura de jovens e adultos camponeses. 2004 Disponível em: $<$ http://miltonborba.org/CD/Interdisciplinaridade/Encontro_Gaucho_Ed_Matem/cientificos/C C35.pdf> Acesso em: junho de 2015.

SILVA, Jonson Ney Dias da; BARBOSA, Jonei Cerqueira. Modelagem Matemática: as discussões técnicas e as experiências prévias de um grupo de alunos. Bolema, Rio Claro (SP), v. 24, no 38, p. 197 a 218, abril 2011. Disponível em: <http://www.redalyc.org/pdf/2912/ 291222086009.pdf> Acesso em: agosto de 2014.

SILVA, Maiana Santana da; BARBOSA, Jonei Cerqueira; OLIVEIRA, Andréia Maria Pereira de. Materiais curriculares educativos sobre Modelagem Matemática e a recontextualização pedagógica operada por professores iniciantes. Revista Iberoameriacana de Educación Matemática. Número 34, 2013, p.47-67. ISSN: 1815-0640. Disponível em: <http://www.fisem.org/www/union/revistas/2013/34/archivo7.pdf> Acesso em: agosto de 2014. 